\title{
CLIMATIC SIGNAL IN TREE-RING CHRONOLOGIES OF CEDRUS DEODARA FROM CHITRAL HINDUKUSH RANGE OF PAKISTAN
}

\author{
NASRULLAH KHAN ${ }^{1}$, MOINUDDIN AHMED ${ }^{2}$ and SYED SHAHID SHAUKAT ${ }^{2}$ \\ ${ }^{I}$ Department of Botany, University of Malakand, Khyber Pakhtunkhwa, Pakistan. \\ ${ }^{2}$ Laboratory of Dendrochronology and Plant Ecology, Department of Botany, Federal Urdu University 75300,
}

Karachi, Pakistan

Received 28 November 2012

Accepted 22 May 2013

\begin{abstract}
Tree-rings are an important tool for the investigation of paleoclimatic records for regions or periods of time with no instrumental climatic data. However, the responses of different species and sites to various climatic parameters are unusual. In the present study, we developed tree-ring-width chronologies of Cedrus deodara from three different sites of Chitral Hindukush range of Pakistan. The study was conducted to understand tree-growth climate relationship and its applicability in proxy climate investigations. The chronologies covered the past 469 to 595 years, with a mean segment length (MSL) ranging from 148 to 223 years. Climatic data obtained from the three weather stations showed strong correlation and was found useful for tree-ring climate relationships.

Correlation Function (CF) and Response Function (RF) analysis showed that spring precipitation (March-May) is a critical limiting factor for tree-ring growth, and temperature prior to November may also play a major role in affecting tree ring-growth. The results exposed that the three sites have continuous relationship indicated that only single species from different locations are affected by the same environmental variables and hence can be used in climate reconstruction in combination. The Cedrus deodara chronologies developed at different locations had several corresponding narrow and wide marker rings indicating a large macroclimatic response to regional climatic conditions. The current study suggests that the tree-rings of Cedrus deodara from the Chitral Hindukush range could be used to develop chronologies for the reconstruction of seasonal climatic variables.
\end{abstract}

Keywords: Cedrus deodara, tree-growth, proxy climate, response function, Hindukush range.

\section{INTRODUCTION}

Dendrochronology is a "young science" and has been expanding rapidly in Pakistan and so far substantial progress has been made since the pioneer work of Champion et al. (1965), Khan (1968) and Sheikh (1985). These workers used Pinus gerardiana, Pinus wallichiana and Juniperus excelsa from Zhob District and Azad JammuKashmir areas for age determination based on simple ring

Corresponding author: N. Khan

e-mail: nasrullahdushkheli@yahoo.com count without applying standard dendrochronological techniques. However, in other parts of the world investigators have used tree rings for a variety of applications, including: silvicultural treatments on managed forests (Guilley et al., 1999; Bridge and Winchester, 2000); reconstruction of past climate (Briffa et al., 2001; Watson and Luckman, 2001; Speer, 2010); reconstruction of insect outbreaks (Swetnam and Lynch, 1993; Speer et al., 2001); reconstruction of past wildfires (Swetnam, 1993; Grissino-Mayer and Swetnam, 2000; Brown et al., 2011); and reconstruction of earth processes (Yamaguchi et al., 
1997; Gartner et al., 2001). In Pakistan these information are scanty and so far very little is known about the dendroclimatic potential of conifers. Among these, conifer Cedrus deodara is an important tree species and declared as the national symbol of Pakistan (Ahmed et al., 2011a; Khan et al., 2012).

Studies have shown that conifers could be used in climatic investigations including Cedrus deodara in the Himalayan region (Ahmed, 1987; Bhattacharya and Yadav, 1999; Yadav and Park, 2000; Singh and Yadav, 2007; Singh et al., 2009; Ahmed et al., 2009, Ahmed et al., 2011b). However, most of these studies were restricted to the western Himalayan region and few studies were conducted in eastern parts and all of them have been based on conifer species (Ahmed et al., 2011b). The eastern parts of the great Himalayan region have extensive forests with a number of species distributed in the moist and dry temperate parts of the country (Ahmed et $a l ., 2006)$. These forested zones were elucidated for dendroclimatic potential of different conifer species by Ahmed et al., 1987. They explained the scope of dendrochronology in Pakistan and mentioned some suitable sites and tree species which could be used in tree-ring analysis. Ring-width series of Juniperus excelsa and Juniperus turkestanica from six different sites in the HunzaKarakorum were used in reconstructing modes of regional climate over the past 500 years by Esper (2000). He derived all reconstructions from trees growing close to the upper timber line (4000 m a.s.l.). Similarly, Esper and Genrt (2001) presented a tree ring reconstruction of climate extreme years since $1427 \mathrm{AD}$ from western central Asia. They classified the extreme growth reactions into event years - reflecting extreme years of individual trees, site point years - reflecting common extreme years within a site, and regional pointer year - reflecting common extreme years within the Karakorum and Tien Shan. Ahmed and Naqvi (2005) established tree-ring chronologies of Picea smithiana from moist and dry temperate forest of Himalayan range of Pakistan and demonstrated that dry temperate sites show low autocorrelation as compared to moist temperate sites. Whereas, Khan et al. (2008) developed a first 343 years (1663-2006 AD) dated tree-ring chronology from Afghanistan adjacent to Pakistan border. They suggested that this species have high dendroclimatic value and more information could be obtained if this chronology were correlated with other regional chronologies of the same species. Good crossdating with high correlation were achieved by Ahmed et al. (2009) for Abies pindrow and Pinus wallichiana from two different climatic zones and concluded that both the species are suitable for paleoclimatic reconstruction back to at least 500 years.

In addition, four conifer tree species from seven catchments in the upper Indus basin were explored for dendrohydrological potential by Ahmed et al. (2010). Based on their encouraging results they concluded that these tree species chronologies have high potential for dendrohydrological investigation. More substantial information regarding the tree-ring chronologies and their potential for dendroclimatic reconstruction is presented by Ahmed et al. (2011a) from northern Pakistan. They used six tree species and 28 chronologies, out of which several species had trees attaining ages of around 700 years. Correlations between site chronologies were consistently seen both between sites of the same species and between sites composed of different species. They also demonstrated that strong elevational gradient was present in this mountainous region which lends support to the practice of multi-species combination for better spatial and temporal coverage. This network of tree-ring chronologies led to the reconstruction of upper Indus basin river discharge level covering the period AD 1452-2008. However, there is still a considerable gap to explore some other promising sites which are expected to be sensitive to climate regime. Such sites are more desirable for the enhancement of tree-ring research (Fritts, 1976; White, 2007). Because, better understating of the spatial patterns in climate change variability requires expansion of sample collections over diverse areas (Huang and Zhang, 2007). Publications have shown that tree-ring chronologies provide valuable data bases for the enhancement of meteorological records (Pant and Borgaonkar, 1983; Ramesh et al., 1985; Hughes and Davies, 1987; Yadav and Bhattacharyya, 1994; Bhattacharyya and Yadav, 1992. But there is a paucity of weather stations in the vast region of northern Pakistan and the observed climatic records in these stations are usually of relatively small duration (around 40 years) with some missing information (Archer and Fowler, 2004; Ahmed et al., 2009). The lack of such information has hindered our ability to obtain a comprehensive long term climatic variability over large spatial scale (Huang and Zhang, 2007). Therefore, it is critical to develop long time-series of high resolution proxy data back in time for better understanding of the past climate variations (Cook et al., 2003; Zhang and Zhang, 2011). Such long-term climatic data series, derived from tree-rings, is desirable since that would be helpful in identifying pre-industrial climate variability, understanding of extra-regional climatic coupling, sequence, phasing and, perhaps more importantly, in distinguishing natural variations from anthropogenic causes (Yadav et al., 1997).

In this context previous studies demonstrated that the conifers including Cedrus deodara possess great potential and are recommended for climatic investigations due to the fact that the tree species exhibits positive tree-ring characteristics such as old age (longevity), good sensitivity and shows promising response to climate (Ahmed et al., 2011a, 2011b). In view of these considerations, the present study was conducted, and an attempt was made to report the dendroclimatological potential of Cedrus deodara from Chitral Hindukush range of Pakistan. The aims of the study were to develop multi-century long tree-ring chronologies for the species and to explore the relation- 
ships between tree-ring growth and climatic variables. These findings are expected to provide baseline data for the regional climate variability in the past.

\section{MATERIALS AND METHODS}

\section{The Study Area}

Chitral Mountains are located in the Hindukush range of Pakistan that lies in the extreme north east of Malakand division Khyber Pakhtunkhwa (Khan et al., 2010). The area is parallel to the pan shaped Wakhan corridor of Afghanistan (Fig. 1) spanning from $35^{\circ} 13^{\prime}$ and $37^{\circ} 50^{\prime} \mathrm{N}$ latitude and $71^{\circ} 12^{\prime}$ to $73^{\circ} 45^{\prime} \mathrm{E}$ longitude (Manfred and Zimmer, 2000; Ali and Qaiser, 2009). Geographically the area is bordered on the east by district Ghizer of GilgitBaltistan Province while Dir, Swat and Kunar (province of Afghanistan) lie in the south (Jan, 1997; Sethi, 2001). Nuristan province lies across the border to the west and on the Northwest by Wakhan corridor which separates Pakistan and Tajikistan (Jose, 1987; IUCN, 2004; Ali and Qaiser, 2005). Sample collection was conducted the 2 valleys, i.e. Chitral Gol and Bumburate located near Drosh and Chitral meteorological stations with elevation range between 1329 to $7708 \mathrm{~m}$ a.s.l. Sixty percent of the study area is situated at elevation above $3000 \mathrm{~m}$, which is perennially snow-covered (Ajaz, 2004; Zarif, 2004). The runoff-source area below the snow line, at elevations of 1500 to $3600 \mathrm{~m}$, is well vegetated and has ample precapitation (Alamgir, 2004). The district is mainly located in the dry temperate zone of Pakistan with an elevations range from 1070 to $7708 \mathrm{~m}$ creating many local climatic and vegetation zones.
Although the area is predominately arid, there is wide floristic variety of forest and non-forest vegetation due to the variety of ecological zones. Mixed conifer forests form an important zonal vegetation type in the area (Khan et al., 2010) and are distributed between 1800-2900m a.s.l. on either side of River Kunar (Ajab, 1993; Ahmed, 1998). Cedrus deodara is the national tree symbol and the large evergreen tree with its natural distribution all along the Hindukush and Himalaya at altitudes ranging from $1800-5000 \mathrm{~m}$ a.s.l. (Nasir and Ali, 1972; Ahmed et al., 2011b). Tree-ring samples in form of cores of the species were collected at three valleys and three sites near the upper tree line in the Chitral Gol, Bumburate and Ziarat (Fig. 1; Table 1). The environments of the sites vary considerably in terms of topography and forest composition. The site at Kalash valley $(2283 \mathrm{~m})$ has steep slope $\left(62^{\circ}\right)$ whereas, at Chitral Gol and Ziarat with comparatively low elevations and degree of slopes (Table 1). The main associates of Cedrus are Pinus gerardiana, Pinus wallichiana, Picea smithiana, Abies pindrow, Juniperus excelsa, Quercus baloot and Quercus dilitata in the study area (Fig. 2). The sites were deterministically chosen for sampling with the considera-

Table 1. Site characteristics for five tree-ring sampling sites in the Chitral mountains.

\begin{tabular}{llccccc}
\hline Site & Species & Long. (E) & Lat. (N) & Elev. (m) & Aspect & Slope \\
\hline Kalash & CD & $71^{\circ} 38$ & $35^{\circ} 41$ & 2283 & NE & $62^{\circ}$ \\
Chitral Gol & CG & $71^{\circ} 40$ & $35^{\circ} 56$ & 2331 & W & $28^{\circ}$ \\
Ziarat & CD & $71^{\circ} 48$ & $35^{\circ} 21$ & 2900 & NW & $27^{\circ}$ \\
\hline
\end{tabular}

Note: $C D=$ Cedrus deodara, Long = Longitude, Lat = Latitude

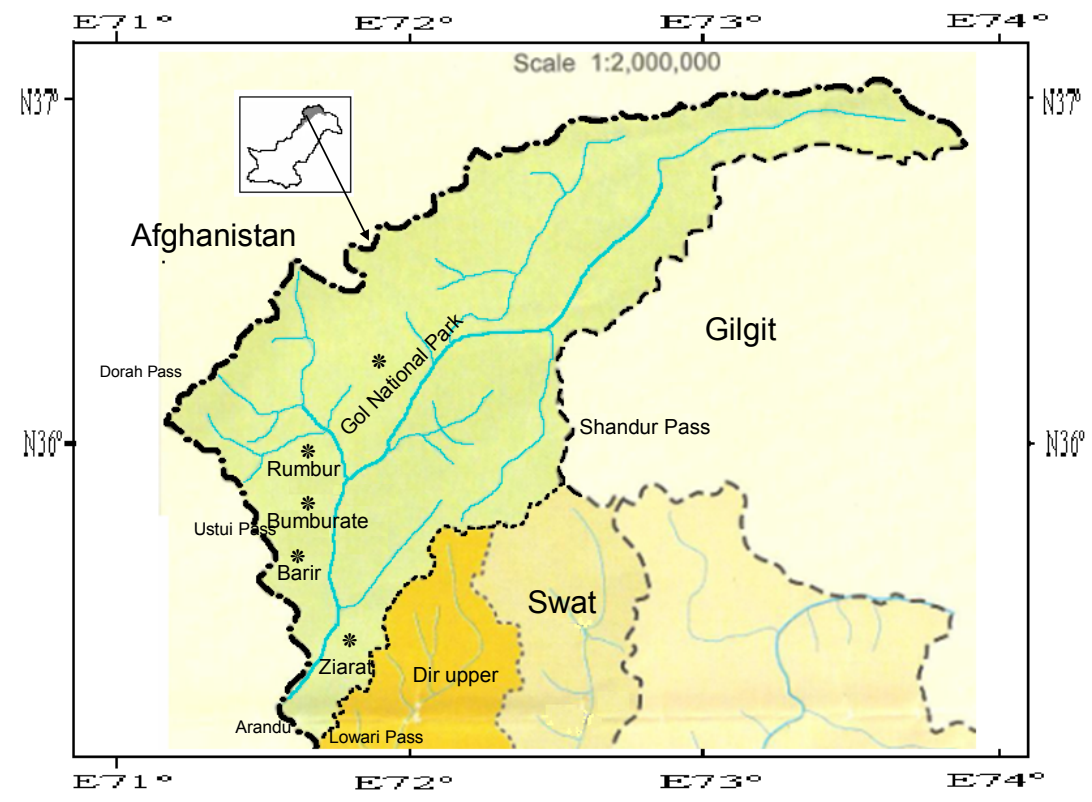

Fig. 1. Location of tree-ring sampling sites are shown with stars. 
tion that they were subjected to least anthropogenic disturbance. Two increment cores per tree contingent upon the accessibility were obtained on $90^{\circ}$ and as a result 19 to 27 samples for individual tree species were gathered (Table 2).

\section{Dating and chronology preparation}

The wood sample in the form of cores were air-dried, mounted, and sanded with progressively finer grade sandpaper in order to achieve a shiny surface of tree-ring boundaries (Stokes and Smiley, 1996). The prepared samples were subjected to standard dendrochronological techniques for visual cross-dating by employing skeleton plot procedure following the method outlined by Fritts (1976) and Cook and Kairiukstis (1990). This procedure

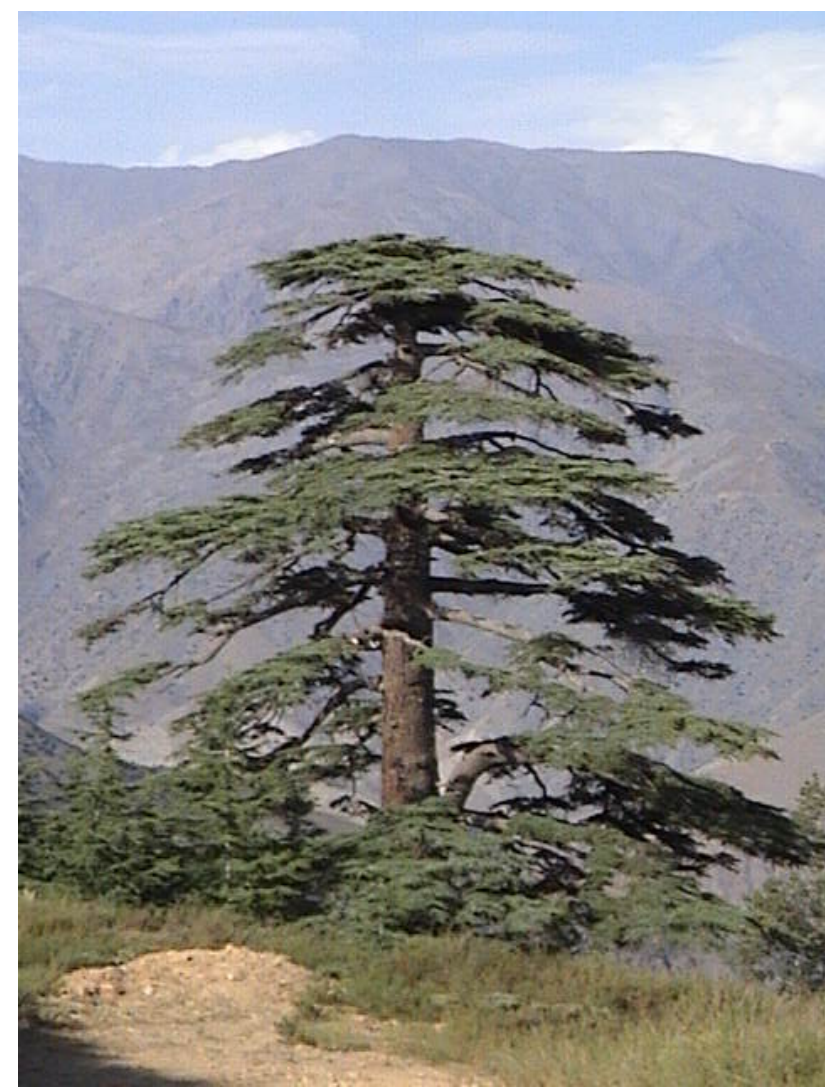

Fig. 2. Cedrus deodara (National symbol of Pakistan) at Chitral Gol National Park site. enabled us to detect the problematic zones such as narrow or false rings and some of these were removed before continuing with the analysis (Grissino-Mayer, 2003; White, 2007. The visual cross-dated ring-width sequences were measured using VELMEX measuring system comprising of a microscope, movable stage joint with $\mathrm{J} 2 \mathrm{X}$ measurement software. The individual ring measurements were obtained to the nearest $0.001 \mathrm{~mm}$. In the next step the visual cross-dating ring width measurements were ensured using the quality control program COFECHA (Holmes, 1994; Grissino-Mayer, 2001). Poor correlation among many radii led to the rejection of few core samples for further analysis similar to the practice of Yadav et al. (1997). Finally, we selected 19 cores from 10 trees of Kalash valley, 27 of 16 trees of Chitral Gol and 23 samples from 16 trees of Ziarat valley for chronology preparation.

The measured series of individual dated sample was transformed to ring-width indices by employing ARSTAN software (Cook, 1985, Holmes, 1994). This procedure was practiced to remove age and other nonclimatic trends and involved fitting a spline that was two thirds the length of the common period of the tree-ring series (Heinrich, 2004). The Expressed Population Signal (EPS; Wigley et al., 1984) was used to assess the loss of common variance over time with decreasing sample size for all the chronologies. The chronologies were truncated when EPS dropped below the value 0.85 . We used the three standardized tree- ring chronologies of Cedrus deodara in order to obtain various statistics that would be helpful in the exposition of the dendroclimatic potential in the climate change scenario. In addition, these chronologies will be useful to detect the potential of the species for the reconstruction of climate and river flow in the area in future.

\section{Climatic Data}

The climatic data derived from the meteorological stations located in close proximity of the sampling sites is suggested by workers for better interpretation of treegrowth climate relationships (Yadav et al., 1997; Heinrich, 2004). However, in northern Pakistan, meteorological stations with long, homogeneous records are few and usually located far from the forested areas or tree-ring study sites (Ahmed et al., 2009; Ahmed et al., 2011a). The climatic parameters from any such single station

Table 2. Summary statistics of tree-ring width chronologies of Cedrus obtained from three different sites.

\begin{tabular}{cccccccccc}
\hline $\begin{array}{c}\text { Chronology } \\
\text { Sites }\end{array}$ & $\begin{array}{c}\text { No. of sam- } \\
\text { ples }\end{array}$ & $\begin{array}{c}\text { Chronology } \\
\text { Span }\end{array}$ & $\begin{array}{c}\text { MAl } \\
(\mathbf{m m})\end{array}$ & MSV & $\begin{array}{c}\text { SD } \\
\text { Mm }\end{array}$ & RBAR & SI & AR & EPS \\
\hline CDK & $(10) 19$ & $1411-2006$ & $0.88(0.587 / 6.14)$ & 0.227 & 0.587 & 0.442 & 0.667 & $0.877-0.006$ & 1670 \\
CDCG & $(16) 27$ & $1537-2006$ & $1.44(0.714 / 7.29)$ & 0.210 & 0.714 & 0.287 & 0.637 & $0.853-0.002$ & 1730 \\
CDZ & $(16) 23$ & $1472-2005$ & $1.49(0.728 / 8.34)$ & 0.213 & 0.728 & 0.471 & 0.539 & $0.824-0.001$ & 1960 \\
\hline
\end{tabular}

MAI: Mean (min/max.) annual increment; MSV: mean sensitivity value; SD: standard deviation; RBAR: mean correlation coefficient between all treering series used in a chronology; SI: Series Intercorrelation; AR: variance related to autoregression; EPS: 1st year expressed population signal 0.85. 
cannot be assumed to be representative of regional climate and may not provide ideal data for calibrating treering data from distant sites (Mitchell et al., 1996). In such cases averaging of two or more meteorological station records avoids many problems associated with record inhomogeneities and deferring station microclimates so that they can provide potentially more reliable data to calibrate tree-ring chronologies (Blasing et al., 1981; D'Arrigo and Jacoby, 1993; Jacoby et al., 2000). In addition, Fritts (1976) and Pant and Borgaonkar (1984) suggested the use of climatic data of stations located even at some distances from the tree-ring sites for the calibration of tree-growth climate relationships.

In the present study, we have employed climatic data of temperature and precipitation from Drosh (1400 m a.s.l.) and Chitral meteorological stations (1350 $\mathrm{m}$ a.s.l.) around $100 \mathrm{~km}$ of the sampling sites for tree-ring calibration in the Response function (RF) analysis. As some years in the monthly annual data were missing for both the stations for climatic variables. Therefore, we used average monthly temperature and total precipitation data for the period starting from 1965-2009. The location and type of data for both the parameters (temperature and precipitation) have not changed and the data for both the stations were tested and found homogenous for the entire period following Mitchell et al. (1996) and Heinrich (2004). The two climatic parameters for both the stations were found to be strongly correlated $(r=0.999, \mathrm{P}<0.001)$ using Pearson product moment correlation for the entire period. However, the homogeneity plots for mean temperature and precipitation of Dir station exhibit inhomogeneities which were excluded from analysis.

\section{Tree growth-climate relationship}

Correlation and Response function analyses were used for the exploration of tree-growth climate relationship (Fritts, 1976). However, the response function (RF) techniques were used with the modification of Guiot et al. (1982) and Cook (1985). Among the three discrete versions of chronologies standard version was preferred due to the lag year effect (White, 2007; Yuan et al., 2007). The selected chronology of each site and local climatic data (precipitation and temperature) were treated separately in the response function analysis. Average monthly temperature and total monthly precipitation starting from previous October to August of the current growth year were used. Mean monthly temperature and total precipitation is recommended by Fritts (1976) to perform adequate response function analysis. Forty three years climatic data (1965-2009) were taken for response function analysis. Gordon (1980) and Blasing et al. (1981) have suggested that a minimum 42 years predictors (ring-width data) and predictands (climatic record) is required to perform a reliable response function analysis. Correlations were also calculated between tree-ring chronologies and climatic data over multi-month seasons following Huang and Zhang (2007). Bootstrap method of
Guiot (1991) was followed for the test of significance of response coefficients derived from response function analysis.

\section{RESULTS}

\section{Tree-ring chronology development}

The tree ring-width chronologies of Cedrus deodara from three different sites of Chitral Hindukush range of Pakistan (Table 2; Fig. 3). The chronologies covered the past 469 to 595 years, with a mean segment length (MSL) ranging from 148 (TC) to 223 years (BD). Cedrus deoda$r a$ at Bumburate Kalash valley exhibited an age range from 128 to 596 years while the chronologies from individual sites of Chitral Gol and Ziarat valley furnished a 469 and 533 years tree-ring chronology respectively. These chronologies were obtained between an altitudinal range of $2283 \mathrm{~m}$ to $2900 \mathrm{~m}$ a.s.l. and 27 to $62^{\circ}$ moderate slopes (Table 1). Out of 42 trees (69 samples) 7 samples were found in the age range between 200 to 300 years, 6 were above 300 years while 2 samples attained ages above 550 years (Fig. 3). These sites are located on northeast, north and northwest aspects consisting of generally slow growing trees with a mean annual increment between 0.88 and $1.49 \mathrm{~mm}(1.27 \pm 0.10 \mathrm{~mm})$. The standard deviation (stdv) of the raw values follows the rules that slow growing trees in these sites have low variance $(0.587-0.728 \mathrm{~mm})$. However, the value of mean sensitivity (MS) characterizing the year to year variability in treerings was almost similar and relatively high (0.21-0.227) compared to that of other species. The sites chronologies in terms of their quality regarding the usefulness for dendroclimatic studies were evaluated. The statistics of the chronologies showed that the EPS values attained were generally within recommended threshold value of 0.85 for the Chitral Gol site, Kalash and Ziarat valleys. The chronologies indicated that the early part of the chronologies has small sample size and limited to the year when the value for EPS dropped below 0.85 which resulted the cut-off in 1670 for Chitral Gol, 1730 for Kalash valley. Wheras, Ziarat chronology hold this value up to 1960 which is comparatively low from the prior two chronologies sites (Table 2). In addition, the running Rbar displayed high variability over time, this statistics was rather stable during the robust intervals (EPS $>0.85$ ) of the chronologies.

The results disclosed that elevation also plays an important role in the growth pattern of Cedrus deodara in the study area. In comparison to the 2 chronologies at high elevations the tree-ring series at a low elevation have high mean ring width and standard deviation values (Table 2). The signal to noise ratio (SNR) in tree-rings ranged from 8.1 to 19.0 , indicating that the ring width data had some autocorrelation $(0.82-0.87)$ that was presumably caused the biological feedback. The relatively high values of intercorrelation being higher $(0.53-0.66)$ 

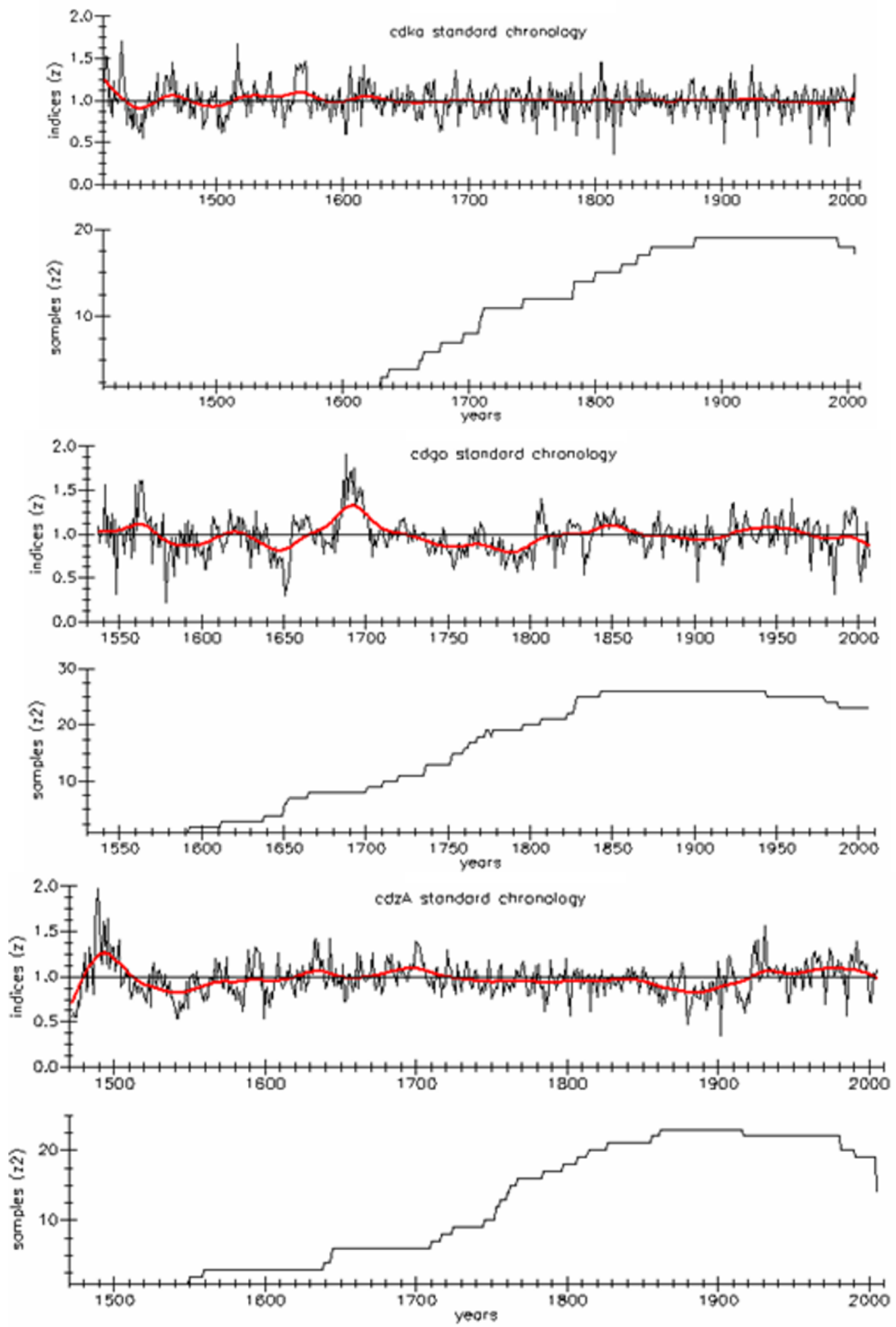

Fig. 3. Standard tree-width chronologies of Cedrus deodara (top) with averages and a sample size (bottom) from Bumburate Kalash Valley, Chitral Gol National Park and Ziarat sampling Sites. 
for the low elevation. The relatively high level of VFE (Variance in First Eigenvector) (20.9 to 28.6\%) indicating strong common signals among the trees constituting the mean chronology. Therefore, our tree-ring chronologies provided a robust estimate of the mean tree growth and are suitable for dendrochronological analysis.

The presence of a common climatic signal in the three chronologies was confirmed by the time span overlap analysis (TSOA). The cross correlations (CC) among the different site chronologies were tested for a common period of 100 years (1900-2000) time span. Correlation matrix $(\mathrm{CM})$ of tree-ring width indices illustrate that Cedrus deodara from Chitral Gol site exhibited strong relationship $(\mathrm{r}=0.67, \mathrm{P}<0.001)$ with Kalash valley and Kalash valley with Ziarat site $(\mathrm{r}=0.54, \mathrm{P}<0.01)$ and Ziarat with Chitral Gol $(r=0.65, \mathrm{P}<0.001)$ respectively. The high values of the first-order autocorrelation (AR; $0.82-0.87$ ) are an indication of the low frequency variance embedded in the series, and could be explained by climate or by the lagged response of tree physiology. In addition, ARSTAN program computed overlapped time span in order to demonstrate the correlation between each sample. The statistical properties of different tree series resulting from ARSTAN for a common period are shown in Table 3. The results indicated that the mean correlation among all radii ranged between $0.32-0.37$ and the eigenvector ranged between 21.8 and $45 \%$. The mean correlation among all radii, mean correlation between trees, mean correlation within trees and variance associated with first eigenvector demonstrate that the species ring-width exhibited high correlation within trees. These results revealed that Cedrus deodara not only display strong correlation among samples of the same sites but also with different sites.

The extreme common narrow and wider rings in Cedrus deodara in the three different sites chronologies in the present study site were recorded. The years of narrow rings including the years 2001, 1999, 1998, 1995, 1988, 1984, 1952,1921, 1915, 1900, 1882, 1878, 1848, 1808 , and 1752 , while the wider rings appear in years $1932,1920,1870,1810,1752,1688,1608,1511,1460$ and 1420 respectively.

\section{Growth/climate relationship}

The results of the correlation function from the three different tree-ring sites using standard chronologies and climatic data from Chitral meteorological station (CMS) (temperature and precipitation) is depicted in Table 4 . The response function (RF) results from the same set of data as used in Table 4 are presented in Table 5. The results in Table $\mathbf{5}$ show temperature from January to May of the current year having a negative correlation with tree-ring width. The exception was April temperature which exhibited a positive correlation for Cedrus deodara at the Kalash tree-ring site. On the other hand, precipita-

Table 4. Correlation coefficients between different tree-ring sites (standard chronologies) and climatic data from Chitral meteorological station (temperature and precipitation data). Only significant responses are shown (i.e. +/-).

\begin{tabular}{|c|c|c|c|c|c|}
\hline & $\overline{C d K}$ & $\overline{C d C G}$ & $\mathrm{CdZ}$ & + & - \\
\hline $\begin{array}{c}\text { pSepT } \\
\text { pOctT } \\
\text { pNovT } \\
\text { pDecT } \\
\text { JanT } \\
\text { FebT } \\
\text { MarT } \\
\text { AprT } \\
\text { MayT } \\
\text { JunT } \\
\text { JulT } \\
\text { AugT }\end{array}$ & $\begin{array}{l}- \\
+ \\
-\end{array}$ & $\begin{array}{l}- \\
- \\
- \\
-\end{array}$ & $\begin{array}{l}- \\
- \\
- \\
-\end{array}$ & 1 & $\begin{array}{l}2 \\
2 \\
2 \\
2 \\
3\end{array}$ \\
\hline $\begin{array}{c}\text { pSepP } \\
\text { pOctP } \\
\text { pNovP } \\
\text { pDecP } \\
\text { JanP } \\
\text { FebP } \\
\text { MarP } \\
\text { AprP } \\
\text { MayP } \\
\text { JunP } \\
\text { JulP } \\
\text { AugP }\end{array}$ & $\begin{array}{l}+ \\
+ \\
+ \\
+ \\
+\end{array}$ & $\begin{array}{l}+ \\
+ \\
+ \\
+ \\
+\end{array}$ & $\begin{array}{l}+ \\
+\end{array}$ & $\begin{array}{l}2 \\
2 \\
3 \\
3 \\
2\end{array}$ & 2 \\
\hline $\begin{array}{l}\operatorname{Lag} 1 \\
\operatorname{Lag} 2 \\
\operatorname{Lag} 3\end{array}$ & & + & + & 2 & \\
\hline $\begin{array}{l}+ \\
-\end{array}$ & $\begin{array}{l}7 \\
3 \\
\end{array}$ & $\begin{array}{l}5 \\
5\end{array}$ & $\begin{array}{l}2 \\
5\end{array}$ & 14 & 13 \\
\hline $\begin{array}{c}\text { Climate } \\
\text { Lag } \\
\text { Total }\end{array}$ & $\begin{array}{l}63 \\
11 \\
74\end{array}$ & $\begin{array}{l}61 \\
22 \\
83\end{array}$ & $\begin{array}{l}52 \\
15 \\
67\end{array}$ & $\begin{array}{c}58 \pm 3.3 \\
16 \pm 3.2 \\
74\end{array}$ & \\
\hline
\end{tabular}

Note. $p=$ previous year, $T=$ temperature, $P=$ precipitation, $C d K=$ Cedrus deodara from Kalash, CdCG=Cedrus deodara from Chitral Gol, CdZ= Cedrus deodara from Ziarat.

Table 3. Time span overlap analysis of tree-rings chronologies in each site derived from ARSTAN program.

\begin{tabular}{|c|c|c|c|c|c|c|c|}
\hline \multirow{2}{*}{\multicolumn{2}{|c|}{ Time span overlap }} & \multirow[b]{2}{*}{ No, of trees overlap } & \multirow[b]{2}{*}{ No, of radii overlap } & \multirow{2}{*}{$\begin{array}{l}\% \text { variance in } 1{ }^{\text {st }} \text { eigen- } \\
\text { vector }\end{array}$} & \multicolumn{3}{|c|}{ Mean correlation } \\
\hline & & & & & Among all & $\begin{array}{c}\text { Between } \\
\text { trees }\end{array}$ & $\begin{array}{c}\text { Within } \\
\text { trees }\end{array}$ \\
\hline 1879 & 1992 & 10 & 19 & 41 & 0.368 & 0.311 & 0.360 \\
\hline 1843 & 1979 & 13 & 25 & 45 & 0.378 & 0.317 & 0.434 \\
\hline 1827 & 1990 & 15 & 20 & 21.8 & 0.32 & 0.098 & 0.194 \\
\hline
\end{tabular}


tion has a strong positive correlation with tree growth from February to June of the current year for all the sites. Response function (Table 5) shows a similar trend of positive and negative responses from March to May temperature of the current year for the species. However, previous December exhibited a negative correlation with tree growth in Bumburate Kalash and Gol National Park chronologies (Table 5). Cedrus deodara from Ziarat site shows a positive correlation from June to August of the current year. This trend was not observed in the correlation function $(\mathrm{CF})$. The response of precipitation was quite similar for both the approaches with the exception of a negative and positive correlation in the month of current August.

In addition, some positive responses of precipitation in the month of October (labelled OctP) and December (DecP) of the previous year at Kalash was obtained. However, negative correlations in November (NovP) of the previous year were also recorded in both techniques (Tables 4 and 5). It is worthwhile to mention that the lag years contributed only 2 positive significant coefficients for Cedrus deodara in correlation function while response function yields 4 positive coefficients which are double than that obtained from the correlation function. The overall positive coefficients were 14 while the negative coefficients were 13 in the correlation function. This shows that both temperature and precipitation are significant. Beside the results of correlation function the response function resulted in 20 positive and 13 negative coefficients, which is almost similar to those obtained by the correlation function and the pattern appears consistent. From the results it is obvious that temperature tends to be negative for late winter and spring months. Whereas, precipitation is positive and generally concentrated between February and June of the current year. The correlation function shows an average of $58 \pm 3 \%$ variance that is explained by the climate and $16 \pm 3 \%$ by the lag years. The overall variance (i.e. climate + lag) obtained was $74 \pm 3 \%$ for all the sites. The response function analysis does not give the explained variance making this one of the drawbacks of this technique. In general, a relatively large amount of variance (67-83\%) was obtained for all sites and the patterns were similar and consistent.

\section{DISCUSSION AND CONCLUSIONS}

\section{Tree-ring chronologies}

Tree ring data of Cedrus deodara were tested for their suitability for further study of dendroclimatology. Several other workers also reported that redial growth of this species is sensitive to climate in the eastern and western Himalaya (Bhattacharyya et al., 1992; Pant et al., 2000; Yadav, 2013; Ahmed et al., 2011a; Wahab, 2011). In the present study, the samples of Cedrus deodara correlate well with the site mean. The autocorrelation value at 3 locations of Cedrus deodara was low and the mean sensitivity was high. Consequently, on the basis of low auto-
Table 5. Response coefficients between different tree-ring sites (standard chronologies) and climatic data from Chitral climatic station (temperature and precipitation data). Only significant responses are shown (i.e. +/-).

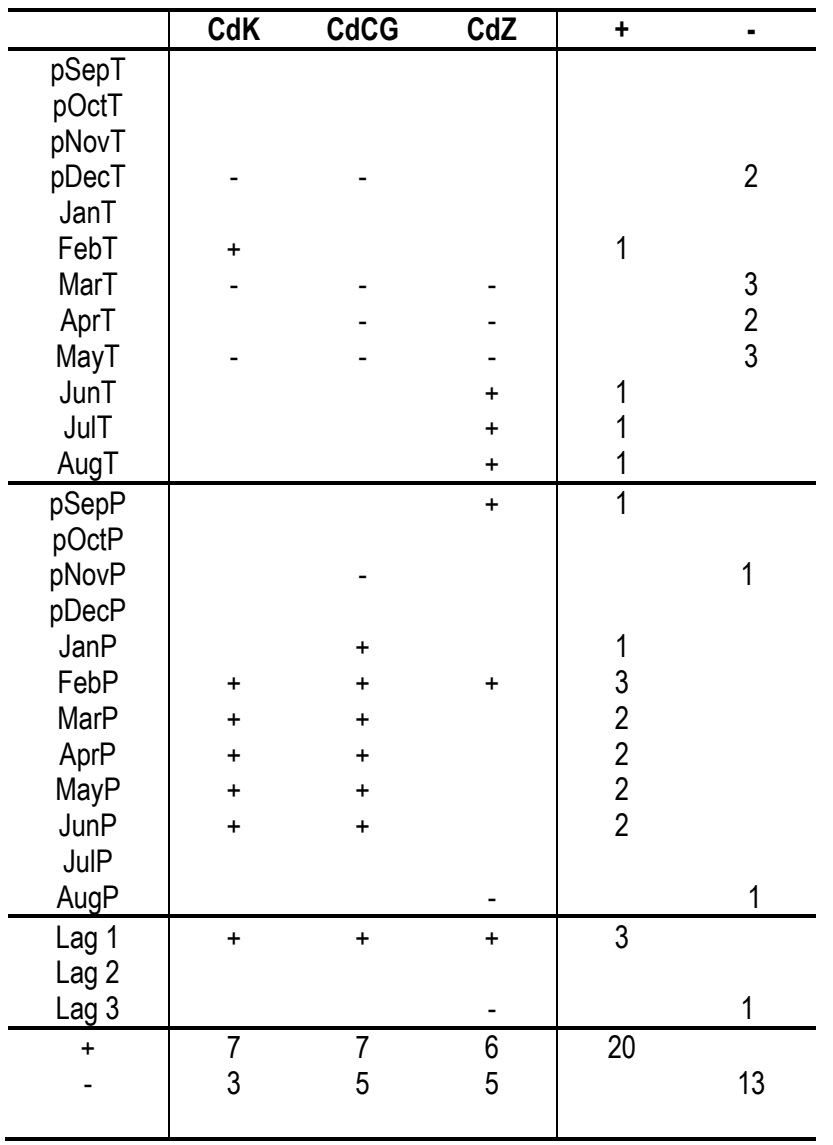

Note. $p=$ previous year, $T=$ temperature, $P=$ precipitation, $C d K=$ Cedrus deodara from Kalash, CdCG=Cedrus deodara from Chitral Gol, CdZ= Cedrus deodara from Ziarat.

correlation at these locations of Cedrus deodara, it is suggested that the tree samples do contain some climatic information. The values of mean sensitivity reported in the present study were in the range values reported by other workers for the species (Bhattacharyya et al., 1992; Borgaonkar et al., 1996; Pant et al., 2000; Ahmed et al., 2009, Ahmed et al., 2010). This gives evidence that the species is suitable for further dendroclimatic investigations, including climatic reconstruction for temperature and precipitation.

As for as the individual chronology of the species are concerned, the Kalash chronology was the longest at 596 years (1411 to 2006), followed by Ziarat site chronology at 534 years (1472 to 2005) and Chitral Gol National Park at 470 years (1537 to 2006). From these results it is noteworthy that the Cedrus trees used in these chronologies are long lived and exhibited great age that extend significantly beyond the period of modern climate recorded history (1895-present). It is argued that modern 
records are used to calibrate climate reconstruction (Fritts, 1976; White, 2007). Fritts (1976) has reported that older trees should be targeted for sampling at sensitive sites in order to extend the chronologies further back in the time frame beyond the calibration period. In the present study many increment core samples from each site in the chronologies were not included due to time constraints and small sample size. Additionally, in some tree samples could not be cross-dated well because of irregular growth (problematic zone) and complacent ring patterns. Consequently, these cores were not included in the present study.

The comparison of the correlations between different chronologies from the same site and from neighbouring locations exhibited strong correlation $(\mathrm{P}<0.01)$ within site and from different sites of the same species. This continuous relationship between sites indicated that only single species from different locations are affected by the same environmental variables and hence can be used in climate reconstruction in combination. These findings are in agreement with those of Battachachryya et al. (1988); Ahmed et al. (2010) and Ahmed et al. (2011a) who reported high mean sensitivity and good intra-species correlations.

The Cedrus deodara chronologies developed at different locations had several corresponding narrow marker rings indicating a large macroclimatic response to regional climatic conditions. These extremely narrow rings were also reported by other workers (Esper and Genrt, 2001, Esper et al., 2001; 2002; Ahmed et al., 2010; Zafar et al., 2010) in the same species and even in other species. Some of the negative and positive extreme years listed by Wang et al. (2004) and Huttametta (2004) of other conifers from the neighbouring countries also correspond with exceptionally narrow and wider rings found in Cedrus deodara in the present study sites. However, Hughes et al. (2001) described a signature year if more than 18 out of 23 chronologies exhibit the same growth trend. Therefore, our results are not directly comparable. In the present study negative pointer years with a wide distribution within the study area are more common than positive years similar to that reported by Huang and Zhang (2007). A similar case of pointer years were also reported by Pourtahmasi et al. (2007) using Juniperus polycarpos. They concluded that the use of pointer years in climatic analysis and their relationship to certain modes of the atmospheric circulation can provide a base for the interpretation of a similar distribution pattern of pointer year's further back in time. Our initial study indicated that pointer years in Cedrus can be assigned to distinct local climate anomalies and thus can be utilized in inter-regional tree-ring network to evaluate the distribution and intensity of regional circulation pattern.

The Cedrus deodara had the greatest interseries correlation ( $\mathrm{r}=0.67$ to 0.88$)$ and mean sensitivity. Greatest sensitivity and correlation of $C$. deodara at Chitral Gol was likely, because tree growth at this location was lim- ited more singularly by precipitation, whereas, the temperature variable had greater influence on the growth at Kalash valley. A reliable sample depth may also be achieved by using expressed population signal (EPS) which was high for these sites (Heinrich, 2004; White, 2007). Therefore, it is suggested that Cedrus deodara on these sites requires extended sample size for reliable statistical estimates and cross-dating beyond 1750 and $1830 \mathrm{AD}$, respectively.

In the present study, an attempt was also made to check the homogeneity of the meteorological data for the three, i.e. Chitral, Drosh and Dir, meteorological stations so as to avoid the influence of systematic errors during the statistical comparison of tree-rings and climatic data. The comparatively low correlation patterns among different environmental variables of Dir meteorological station with the other two stations might be partly explained due to the larger distances and closeness of the station towards the moist temperate area like Upper Kohistan. It is also worthwhile to mention that Drosh is located near the Dir station, while Chitral is closely located to Drosh meteorological station. However, the overall outcome demonstrates strong correlation among climatic parameters of the three stations. Based on these results it was concluded that the climatic data of Chitral meteorological station could be used for further analysis due to the close proximity of the tree-ring sites.

\section{Tree growth-climate relationship}

Tree-ring width and climate were tested using both approaches, i.e. the correlation function and response function and it was concluded that was no marked difference in the results from both approaches. However, it is suggested that correlation function is better to use for further analysis because of two reasons: (1) the consistent results from both approaches means that there is no real advantage to using both methods all the time; only one method is sufficient, (2) the correlation function method provides some additional insights by having the amount of variance explained included as a part of the output. This view is supported by Blasing et al. (1984) who noted that the response function can be affected in unpredictable ways by often subjective decisions about the number of climate variables to include, confidence limits, number of eigenvectors to allow as candidate predictor in regression etc. Since correlation functions are more objective and easy to interpret. Copper, (1985) and Morzukh and Ruark (1991) have stated that in response functions, normal significance levels of coefficients are misleading because error estimates are underestimated, hence some coefficients can erroneously pass the test of significance. This usually causes greater number of significant coefficients in response functions than in correlation functions (Villalba, 1994; Biondi and Waikul, 2004).

The growth climate response showing the direction and magnitude of the effect of climatic variables on tree growth are shown for Cedrus deodara from all the sam- 
pling sites exhibited high number of significant responses. The significant positive elements of precipitation were higher than that of temperature (Tables 4 and 5). Both types of approaches show negative response to temperature and positive response to precipitation in the month of April. This response was consistent in all chronologies. However, negative temperature response in previous October and from March to June and positive in April and May is evident from all chronologies. Correlation function analysis of Cedrus deodara chronologies has shown that temperature of current January and February exhibited a negative relationship with tree growth. It is evident that temperature of the current May has significantly negative effect while rainfall shows significant positive relationship in the month of April and May. It is noteworthy that all the sampling sites in the present study area are located on relatively high elevation in the zone of snowfall. Ahmed et al. (2009) has found that positive rainfall response at high altitudes is not clear, especially in the winter season. However, in the present study sites, the significant negative relationship of temperature and positive precipitation response can easily be explained for the months of May and June respectively. During May and June more than average temperature (significant negative) may result in a reduced growth in plants due to increased evapotranspiration and water deficit in the soil. Therefore, in such conditions more than average precipitation (significant positive) encourages growth. These results are supported by the findings of Yadav et al. (1997) who reported that the negative influence of temperature on tree growth is reasonable as the summer is very hot and dry at moderate elevation. Similar type of response is also reported by Ahmed et al. 2009a, 2009b) for Picea smithiana at Astore and Nalter for Abies pindrow from Murree and Ayubia. However, the present study sites are located on comparatively low elevation than Astore, Murree and Ayubia sites. This indicated a strong growth climate response on a wide area, despite the fact that these site and species are located away from each other and even in different climatic zone. Yadav et al. (1997) has described that site condition plays an important role in influencing the growth response of tree to monthly climatic variables. In the present study sites, some differences were evident that may be attributed to the site disparity. However, the general response of the species show similar trend despite the fact that there are differences with respect to topographical factors. As mentioned earlier, Cedrus deodara occurring sympatrically at Kalash site and Gol National Park site show strong intra-specific correlation with almost similar response to climatic variables. This indicates that this set of sites for the same species would be of great importance in the development of a wider network and possible combination. These results also accord with those reported by Singh et al. (2009) using the same species.

The correlation analysis has been carried out between the seasonal mean climatic variables and tree ring chro- nologies (Table 6). The season considered were previous autumn (SON), winter (DJF), spring (pre-monsoon, MAM), summer (monsoon, JJA) and current autumn (SON). The results revealed that winter temperature has a strong negative relationship with the tree growth of both the species which is difficult to explain. However, it was concluded that precipitation in the spring season has a significant positive relationship $(\mathrm{r}=0.64, \mathrm{p}<0.001)$ while for temperature, it was negative. This means that summer precipitation has a direct relationship with tree growth which is more convenient and easy to explain. The climatic data of the study area show that high amount of precipitation occurs in the spring season, and only $32 \%$ of the total precipitation occurs in monsoon period (Alamgir, 2004). According to Hussain et al. (2007) Chitral is a rain shadow valley and out of reach of monsoon. In the spring season, the temperature increases gradually above the annual average value and May is the hottest month of the season, whereas the amount of precipitation during pre-monsoon period is comparatively high. As this season corresponds with the early part of the active growth period of the trees, due to increased temperature, loss of moisture occurs which affects tree growth, while greater precipitation in this period is conducive to better growth. This view is supported by Borgaonkar et al. (1996) who has reported that pre-monsoon (March-April-May) temperature and precipitation significantly affects the tree growth. As the temperature during this period determines the availability of moisture in the early period of growth

Table 6. Correlation coefficients between different tree-ring sites (Standard chronologies) and climatic data from Chitral met station (temperature and precipitation data dividing into 5 seasons). Only significant responses are shown (i.e. +/-).

\begin{tabular}{c|ccc|cc}
\hline & CdBK & CdCG & CdZ & + & - \\
\hline Temperature & & & & & 2 \\
1PAutumnSON & & - & - & & 3 \\
2WinterDJF & - & - & - & & 1 \\
3SpringMAM & & & - & & \\
4SummerJJA & & & & & \\
5AutumnSON & & & & & \\
\hline Precipitation & & & & & \\
1PAutumnSON & & & & & \\
2WinterDJF & + & + & & 2 & \\
3SpringMAM & + & + & + & 3 & \\
4Summer/JA & & + & + & 2 & \\
5AutumnSON & & & & & \\
\hline Lag 1 & & + & + & 2 & \\
Lag 2 & & & & & \\
Lag 3 & & & & & \\
\hline+ & 2 & 3 & 2 & 9 & \\
- & 1 & 2 & 3 & & \\
\hline Climate & 60 & 59 & 39 & $52 \pm 3.4$ & \\
Lag & 7 & 20 & 28 & $18 \pm 5.2$ & \\
Total & 67 & 79 & 67 & $71 \pm 4.9$ & \\
\hline
\end{tabular}

Note. $C d K=$ Cedrus deodara from Kalash, $C d C G=C e d r u s$ deodara from Chitral Gol, CdZ= Cedrus deodara from Ziarat. 
though the higher temperature accelerates the process of photosynthesis, significant moisture deficiency occurs due to the high rate of evaporation and evapotranspiration. This may largely explain the negative relationship with temperature as we observed in the analysis for Cedrus deodara. Therefore, additional rainfall than average precipitation during pre-monsoon (M-A-M) is very functional in sustaining minimum requirement of moisture and is found to be favourable for tree growth. These results are also in agreement with Borgaonkar et al. (1994) who have reported a similar behaviour of the conifers from Kashmir valley using tree ring chronologies of Picea smithiana and Abies pindrow corresponding to Srinagar climate. However, in their study area May is hot and July is the hottest month with relatively less precipitation. Therefore, it was concluded that slightly excess of precipitation during these months is expected to be better for growth in their study area.

From the above discussion it is evident that high temperatures during the spring season (pre-monsoon) coupled with the availability of water from precipitation during the same period are of critical importance for tree growth. Using this relationship it is possible to reconstruct the pre-monsoon precipitation from this set of chronologies for Chitral area. Singh and Yadav (2005) have stated that the reconstruction of spring precipitation using a network of tree-ring chronologies is of great importance, because spring season climate over the Himalayan region is linked with south Asian monsoon system (Douville and Royer, 1996). However, it is suggested that due to some unexplainable responses, further response function analysis with data from some additional meteorological stations in the analysis of dendroclimatic modelling may be carried out. The interpretation of the present results is simply a guide to the climatic variables that influence tree growth and the direction and relative strength of the relationship until verified by further investigations.

Dendroclimatic analysis seems to indicate that total monthly precipitation is more important than monthly mean temperature. The growth climate response disclosed that generally high precipitation and negative temperature for March to May has a positive effect on tree growth of both the species which is more convincing. Therefore, conclusions were made to reconstruct precipitation for spring season (March-April-May) in future is expected to be beneficial. In the present study, by the application of different approaches were used in order to make decisions for further analysis. It is concluded that correlation analysis is better than response function because the consistent results from both approaches means that there is no real advantage to use both the methods all the time and presumably one method is sufficient. Additionally, the correlation function provides some extra insights by having the amount of variance explained as part of the output. As for as this study is concerned local data is well correlated with the tree ring-width and explained greater proportion of variance than grid data, therefore, local data is recommended for further analysis. From the results it is also evident that there is no substantial difference by using the three discrete versions of chronologies, however, standard chronology was preferred to use for further analysis due to the inclusion of lag years. The results of 15 month window and seasonalized window are consistent, though there is considerable difference in the amount of variance obtained, because with seasonal data the months have been combined together. However, seasonalized window is more convincing in terms of selecting suitable seasons for climatic reconstruction in future.

\section{REFERENCES}

Ahmed M, Khan N and Wahab M, 2009a. Dendroclimatic investigation in Pakistan using Picea Smithiana, A preliminary results. Pakistan Journal of Botany 41(5): 2427-2435.

Ahmed $\mathrm{M}$ and Naqvi SH, 2005. Tree-ring chronologies of Picea smithiana (Wall) Boiss., and its quantitative vegetational description from Himalayan Range of Pakistan. Pakistan Journal Botany 37(3): 697-707.

Ahmed M, Nazim K, Siddiqui MF, Wahab M, Khan N, Khan MU and Hussain SS, 2009b. Description and structure of Deodar forests from Himalayan range of Pakistan. Pakistan Journal of Botany 42(5): 3091-3102.

Ahmed M, Khan N, Wahab M, Hamza S, Siddiqui MF, Nazim K and Khan MU, 2009c. Description and structure of Olea ferruginea (Royle) forest of Dir Lower District of Pakistan. Pakistan Journal of Botany 41(6): 2683-2683.

Ahmed M, Palmer J, Khan N, Wahab M, Fenwick P, Esper J and Cook E, 2011a. The Dendroclimatic potential of conifers from northern Pakistan. Dendrochronologia 29(3): 212-235.

Ahmed M, Wahab M, Khan N, Zafar MU and Palmer J, 2010. Tree-ring chronologies from upper Indus Basin of Karakorum Range, Pakistan. Pakistan Journal of Botany 42: 295-207.

Ahmed M, Khan N and Wahab M, 2010. Climatic response function analysis of Abies pindrow (Royle) Spach. Preliminary results. $\mathrm{Pa}$ kistan Journal Botany 42(1): 165-171.

Ahmed M, Shaukat SS and Siddiqui MF, 2011b. A multivariate analysis of the vegetation of Cedrus deodara forests in Hindukush and Himalayan ranges of Pakistan: Evaluating the structure and dynamics. Turkish Journal Botany 35: 419-438.

Ahmed M, 1987. Dendrochronology and its scope in Pakistan. Proc. 3rd Nat. Conf. Plant Scientist. Peshawar University, Pakistan.

Ahmed T, 1998. Use and Importance of glacial water in Chitral. Chitral: AKRSP.

Ahmed M, Khan N and Wahab M, 2006. Dendrochronological potential of conifers tree species of Himalayan range of Pakistan. Higher Education Commission Report, Islamabad, Pakistan.

Ajab S, 1993. Medicinal plants of Tehsil Mastuj district Chitral (NWFP), M.Sc Botany thesis Department of Botany University of Peshawar Pakistan. 113pp.

Ajaz A, 2004. Non-Timber products: A substitute for livelihood of the marginal community in Kalash valley, Northern Pakistan. Ethnobotanical Leaflets 11: 97-105.

Alamgir KG, 2004. A study on the condition, use, management and trends of major forest types in Chitral District. Report of Chitral Conservation Strategy and IUCN Sarhad Program. P. 111.

Ali H and Qaiser M, 2009. The Ethnobotany of Chitral valley, Pakistan with particular references to medicinal Plants. Pakistan Journal of Botany 41: 2009-2041.

Ali H and Qaiser M, 2005. Sustainable use of plant wealth of Chitral and preparation of Red. Data List (Unpublished report submitted to HEC-Pakistan). pp 1-70.

Archer DR and Fowler HJ, 2004. Spatial and temporal variation in precipitation in the Upper Indus Basin, global teleconnections and 
hydrological implications. Hydrology and Earth System Sciences 8(1): 47-61, DOI 10.5194/hess-8-47-2004.

Bhattacharyya A and Yadav RR, 1999. Climatic reconstructions using tree-ring data from tropical and temperate regions of India. A review. IAWA Journal 20(3): 311-316.

Bhattacharyya A and Yadav RR, 1992. Tree-growth and recent climatic changes in the western Himalaya. Geophytology 22: 255-260

Bhattacharyya A, Yadav RR, Borgaonkar HP and Pant GB, 1992. Growth-ring analysis of Indian tropical trees: dendroclimatic potential. Current Science 62(11): 736-741.

Bhattacharyya A, LaMarche VC and Telewski EW, 1988. Dendrochronological reconnaissance of the conifers of Northwest India. Tree-Ring Bulletin 48: 21-30.

Biondi F and Waikul K, 2004. DENDROCLIM 2002; A C++ program for statistical calibration of climate signals in tree-ring chronologies. Computers \& Geosciences 30(3): 303-311, DOI 10.1016/j.cageo.2003.11.004.

Blasing TJ, Solomon AM and Duvick DN, 1984. Response functions revisited. Tree-Ring Bulletin., 44: 1-15.

Blasing TJ, Duvick DN and West DC, 1981. Dendroclimatic calibration and verification using regionally averaged and single station precipitation data. Tree Ring Bulletin 44: 37-43.

Borgaonkar HP, Pant GB and Kumar KR, 1996. Ring width variations in Cedrus deodara and its climatic response over the Western Himalaya. International Journal of Climatology 16(12): 14091422, DOI 10.1002/(SICI)1097-0088(199612)16:12<1409::AIDJOC93>3.0.CO;2-H.

Borgaonkar HP, Pant GB and Kumar KR, 1994. Dendroclimatic reconstruction of summer precipitation of Srinagar Kashmir India since the late $18^{\text {th }}$ century. The Holocene 4(3): 299-306, DOI $10.1177 / 095968369400400309$.

Bridge MC and Winchester V, 2000. An evaluation of standard oak tree growth in Ruislip woods, West London. Botanical Journal of the Linnean Society 134(1-2): 61-71, DOI 10.1111/j.10958339.2000.tb02345.x.

Briffa KR, Osborn RJ, Schweingruber FH, Harris IC, Jones PD, Shiyatov SG and Vaganov EVA, 2001. Low frequency temperature varition from a northern tree ring density network. Journal of Geograpical Research 106: 2929-2941.

Brown PM, Bhattacharyya A and Shah SK, 2011. Potential for developing fire histories in Chir Pine (Pinus roxburghii) Forests in the Himalayan Foothills. Tree-ring Research 67(1): 57-62.

Champion GH, Seth SK and Khattak GM, 1965. Forest types of Pakistan. Pakistan Forest Institute Peshawar, pp: 238.

Cook ER and Kairiukstis LA, 1990. Methods of Dendrochronology. Dordrecht.

Cook ER, 1985. A time series analysis approach to tree-ring standardization. PhD dissertation, University of Arizona, Tucson.

Cook ER, Krusic PJ and Jones PD, 2003. Dendroclimatic signals in long tree-ring chronologies from the Himalayas of Nepal. International Journal of Climatology 23(7): 707-732, DOI 10.1002/joc.911.

Copper JP, 1985. Tree-ring response functions: An evaluation by means of simulations. Ph.D Dissertation. Laboratory of tree-ring Research. The university of Arizona. Tucson, AZ

D'Arrigo R and Jacoby G, 1993. Secular trends in high northern-latitude temperature reconstructions based on tree rings. Climatic Change 25(2): 163-177, DOI 10.1007/BF01661204.

Douville H and Royer JF, 1996. Sensitivity of the Asian summer monsoon to an anomalous Eurasian snow cover within the MeteoFrance GCM, Climate Dynamics 12(7): 449-466, DOI 10.1007/BF02346818.

Esper J, 2000. Long term tree-ring variations in Junipers at the upper timberline in Karakorum (Pakistan). The Holocene 10(2): 253-260, DOI 10.1191/095968300670152685.

Esper J and Genrt H, 2001. Interpretation of tree-ring chronologies. Erdkunde 55: 277-288.

Esper J, Schweingruber FH, Winiger M, 2002. 1300 years of climate history for Western Central Asia inferred from tree-rings. The Holocene 12: 267-277, DOI 10.1191/0959683602hl543rp.
Esper J, Treydte K, Gärtner H, Neuwirth B, 2001. A tree-ring reconstruction of climatic extreme years since AD1427 for Western Central Asia. Palaeobotanist 50: 141-152.

Fritts HC, 1976. Tree-Ring and Climate. Blackburn Press, Caldwell, New Jersey.

Gartner H, Schweingruber FH and Dikauc R, 2001. Determination of erosion rate by analyzing structural changes in the growth patterns of exposed roots. Dendronologia 19: 81-91.

Gordon GA, 1980. Verification of climate reconstruction. Dendrochonology workshop, Norwich, England, July 7-11, 1980.

Grissino-Mayer HD, 2001. Assessing Cross-dating Accuracy: A Manual and Tutorial for the Computer Program COFECHA. Tree-Ring Research 57(2): 205-221.

Grissino-Mayer HD, 2003. A Manual and Tutorial for the Proper Use of an Increment Borer. Tree-Ring Research 59(2): 63-79.

Grissino-Mayer HD and Swetnam TW, 2000. Century scale climate forcing of fire regime in the Americans south west. The Holocene 10(2): 213-220, 10.1191/095968300668451235.

Guilly E, Herve JC, Huber F and Nepveu G, 1999. Modeling variability of within-ring density components in Quercus petraea Liebl. with mixed effect models and stimulating the influence of contrasting silvicultures on wood density. Annals of Forest Science 56(6): 449-458, DOI 10.1051/forest:19990601.

Guiot J, 1991. The bootstrapped response function. Tree-ring Bulletin 51: $39-41$

Guiot J, Berger AL and Manaut A, 1982. Response function. In the climate from tree rings. Cambridge University Press. Cambridge. $223 \mathrm{pp}$.

Heinrich I, 2004. Dendroclimatology of Toona ciliata. PhD dissertation of Australian National University. pp. 1-234.

Holmes RL, 1994. Dendrochronology Program Manual. Laboratory of Tree-Ring Research. Tucson, Arizona.

Huang JG and Zhang QB, 2007. Tree-ring and climate for the last 680 years in Wulan areas of northeastern Qinghai-Tibetan Plateau. Climatic Change 80(3-4): 369-377, DOI 10.1007/s10584-0069135-1.

Hughes MK, Kuniholm PI, Garfin GM, Latini C and Eischeid J, 2001. Aegean tree-ring signature years explained. Tree-ring Research 57(1): 67-73.

Hughes MK and AiC-Davies, 1987. Dendroclimatology in Kashmir using tree-ring widths and densities in subalpine conifers. In: L. Kairiukstis, Z. Bednarz \& E. Feliksik (eds.), Methods in Dendrochronology-I: East-west approaches: 163-175. International Institute for Applied Systems Analysis/Polish Academy of Sciences.

Hussain F, Shah M and Sher H, 2007. Traditional resource evaluation of some plants of Mastuj, District Chitral, Pakistan. Pakistan Journal of Botany 39: 339-354.

Huttametta A, 2004. Pine tree-ring response to climate and Enso at Ban Wat Chan, Chiang Mai. M.Sc Thesis. Faculty of Graduate Studies Mahidol University. $167 \mathrm{pp}$.

IUCN Pakistan, 2004. Chitral an integrated development vision, Chitral conservation strategy. pp 8-35.

Jacoby G, Lovelius N, Shumilov O, Raspopov O, Kurbinov J and Frank $\mathrm{D}, 2000$. Long-term temperature trends and tree growth in the Taymir region of northern Siberia. Quaternary Research 53(3): 312-318, DOI 10.1006/qres.2000.2130.

Jan SA, 1997. Ethnobotany of Tehsil Mastuj, District Chitral. M.Sc. Thesis. Department of Botany, University of Peshawar.

Jose RS, 1987. Pakistan a travel survival kit. $3^{\text {rd }}$ edition published by Lonely Planet Publication. pp. 160-230.

Khan AH, 1968. Ecopathological observation in Trarkhal Forest. Part. 1 Regeneration status of the forest. Pakistan Journal of Forestry 18: 169-228.

Khan N, 2012. A community analysis of Quercus baloot Griff, forest. District Dir, Upper Pakistan. African Journal of Plant Sciences 6(1): 21-31.

Khan N, Ahmed M and Wahab M, 2008. Dendroclimatic potential of Picea smithiana (Wall) Boiss, from Afghanistan. Pakistan Journal of Botany. 40(3): 1063-1070.

Khan N, Ahmed M, Wahab M and Ajaib M, 2010. Phytosociology, structure and physiochemical analysis of soil in Quercus baloot 
Griff, Forest District Chitral Pakistan. Pakistan Journal Botany 42(4): 2429-2441.

Manfred FB and Zimmer K, 2000. Generation of a 1:00000 Geological map of central Chitral (Hindukush, north Pakistan) by means of GIS-software. Mitteilungender Österreichischen Geologischen Gesellschaft 91: 11-16.

Mitchell JM, Dzerdzeevskii B, Flohn H, Hofmeyr WL, Lamb HH, Rao KN, and Wallen CC, 1996. Climate change. Report of a working group of the commission for climatology, world meteorological organization technical note, 79 , Geneva.

Morzuch BI and Ruark GA, 1991. Principal components regression to mitigate the effects of multicollinearity. Forest Science 37(1): 191199.

Nasir E and Ali SI, 1972. Flora of West Pakistan. Published under P. L. 480, Research project of U.S.A.D., with coordination of A.R.C. Pakistan.

Pant GB and Borgaonkar HP, 1983. Growth rings of teak trees and regional climatology (an ecological study of Thane region). In: R.C. Tiwari \& R.P. Srivastava (eds.), Environmental Management Allahabad Geographical Society, Univ, of Allahabad: 153-158.

Pant GB and Borgaonkar HP, 1984. Growth rate of Chir pines (Pinus roxburghii) trees in Kumaon area in relationship to regional climatology. Himalayan Research and Development 3: 1-5.

Pant GB, Kumar KR, Borgaonkar HP, Okada N, Fujiwara T and Yamashita K, 2000. Climatic response of Cedrus deodara tree-ring parameters from two sites in the western Himalaya. Canadian Journal of Forest Research 30(7): 1127-1135, DOI 10.1139/x00-038.

Pourtahmasi K, Parsapajouh D, Brauning A, Erlangen, Esper J, Schweigruber FH and Birmensdorf, 2007. Climatic analysis of pointer years in tree-ring chronologies from Northern Iran and neighboring high mountain areas. Geoöko 28: 27-42.

Ramesh R, Bhattacharyya SK and Gopalan K, 1985. Dendroclimatic implications of isotope coherence in trees from Kashmir valley India. Nature 317(6040): 802-804, DOI 10.1038/317802a0.

Sethi HN, 2001. The Environment of Pakistan. Peak Publishing London UK (ISBN 1-901458-490). 1-182 pp.

Sheikh IS, 1985. Afforestation in Juniper forests of Balochistan. Pak. Forest Institute, Peshawar.

Singh J and Yadav RR, 2007. Dendroclimatic potential of millenniumlong ring-width chronology of Pinus gerardiana from Himachal Pradesh, India. Current Science 93(6): 833-836.

Singh J, Yadav RR and Walking M, 2009. A 694 year tree-ring base rainfall reconstruction from Himachal Pradesh India. Climate Dynamics 33(7-8): 1149-1158, DOI 10.1007/s00382-009-0528-5.

Singh J and Yadav RR, 2005. Spring precipitation variations over the western Himalaya, India, since A.D. 1731 as deduced from tree rings. Journal of Geophysical Research: Atmospheres 110(D1): D01110, DOI 10.1029/2004JD004855.

Speer JH, 2010. Fundamentals of Tree-Ring Research. 333p. The University of Arizona Press. Tucson.

Speer JH, Swetnam TW, Wickman BE and Young-Blood A, 2001. Change in Pandora moth outbreak dynamics during the past 622 years. Ecology 82(3): 679-697.

Stokes MA and Smiley TL, 1996. An introduction to tree-ring dating. University of Chicago, Press, Chicago.
Swetnam TW, 1993. Fire history and climate change in giant sequoia groves. Science 262: 885-889, DOI 10.1126/science.262.5135.885.

Swetnam TW and Lynch AM, 1993. Multicentury, regional-scal patterns of western spruce budworm out breaks, Ecological Monographs 63(4): 399-424, DOI 10.2307/2937153.

Villalba R, 1994. Climate fluctuations in mid-latitudes of south America during the last 1000 years: their relationship to the southern oscillation. Revista Chilena de Historia Natural 67: 453-461.

Wang SW, Zhu JH and Cai. JN, 2004. Interdecadal variability of temperature and precipitation in China since 1880. Advances in Atmospheric Sciences 21(3): 307-313, DOI 10.1007/BF02915560.

Watson E and Luckman BH, 2001. Dendroclimatic reconstruction of precipitation for sites in the southtern Canadian Rockies. The Holocene 11(2): 203-213, DOI 10.1191/095968301672475828.

White BP, 2007. Dendroclimatological Analysis of Oak Species in the Southern Appalachian Mountains "A Bachelor's Honors Thesis" The University of Tennessee, Knoxville. Pp. 1-69.

Wigley TML, Briffa KR and Jones PD, 1984. On the average of correlated time series with applications in dendroclimatology and hydrometeorology. Journal of Climate and Applied Meteorology 23: 201-213, DOI

$10.1175 / 1520$ 0450(1984)023<0201:OTAVOC >2.0.CO;2.

Yadav RR, 2013. Tree ring-based seven-century drought records for the Western Himalaya, India. Journal of Geophysical Research Atmosphere, 118, DOI: 10.1002/jgrd.50265.

Yadav RR and Park WK, 2000. Precipitation reconstruction using ringwidth chronology of Himalayan Cedar from western Himalaya: Preliminary results. Journal of Earth System Science 109(3): 339345, DOI 10.1007/BF02702206.

Yadav RR and Bhattacharyya A, 1994. Evolution of growth behavior of deodar and blue pine by using tree ring data from Uttarkashi, UP Himalaya. Current Sciences 67: 112-116.

Yadav RR, Bhattacharyya A and Park WK, 1997. Climate and growth relationship in blue Pine (Pinus wallichiana) from the western Himalaya, India. Korean Journal of Ecology 20(2): 95-102.

Yadav RR, Park WK and Bhattacharyya A, 1997. Dendroclimatic reconstruction of April-May temperature fluctuations in the western Himalaya of India since A.D. 1698. Quaternary Research 48(2): 187-191, DOI 10.1006/qres.1997.1919.

Yamaguchi DK, Atwater BF, Bunker DE, Benson BE and Reid MS, 1997. tree-ring dating the 1700 Cascadia earthquake. Nature 389(6654): 922-923, DOI 10.1038/40048.

Yuan Y, Shao X, Yu S, Gong Y and Trouet V, 2007. The potential to reconstruct Manasi River stream-flow in the northern Tienshan Mountain (NW China). Tree-ring Research 63(2): 81-93.

Zafar MU, Ahmed M, Farooq MA, Akbar M and Hussain A, 2010 Standardized Tree Ring Chronologies of Picea smithiana from Two New Sites of Northern Area Pakistan. World Applied Sciences Journal 11(12): 1531-1536.

Zarif MR, 2004. Vegetation baseline study in Chitral Gol National Park N.W.F.P Pakistan. Report.

Zhang JT and Zhang F, 2011. Ecological relations between forest communities and environmental variables in the Lishan Mountain Nature Reserve, China. African Journal of Agriculture Research 6(2): 248-259, DOI 10.5897/AJAR09.386. 